\title{
Does the Human Brain Resort to AI's Deep Learning in Order to Solve Problems
}

\author{
Prof. M S S El Namaki \\ Dean, VU School of Management, Switzerland. \\ Dean (Retired) Maastricht School of Management, MSM, The \\ Netherlands. \\ $\mathrm{CEO}$, Association for Accreditation of International Business Education \\ aaime.net,Dr.el.namaki@gmail.com
}

\section{The problem}

Problem solving is a daily occurrence in business and, also, in human brains. Businesses resort to a variety of modes in order to find an answer to these problems. Human brains adopt, also, a variety of measures to solve their own brand of problems. Artificial Intelligence technologies seem to have been extending a helping hand to business in the search for problem solving mechanisms. Machine learning and deep learning are currently recognized as prime modes for business insight and problem solving. Does the human brain possess competencies and instruments that could compare to the deep learning technologies adopted by $\mathrm{AI}$ ?

This will be the focus of the following article.

The article is eclectic. It draws on concepts and frameworks from psychology, neurology and management. It starts with 
This is a limited preview of the chapter.

To read the full-text chapter, get access by purchasing this chapter or consider buying the complete book. If your library has subscription to EBSCOhost, the chapter including other chapters of the book can be accessed through your library.

This chapter is a part of the book, 'Management of Data in AI Age' ISBN (paperback): 978-8I-948483-4־9; ISBN (ebook): 978-8I$948483-5-6$

Book DOI: https://dx.doi.org/Io.46679/isbn9788194848349 Chapter DOI: https://dx.doi.org/I0.46679/isbn9788I9484834903 
cases, could be structured or unstructured, functional or multifunctional, conceptual or applied, short or long term, high risk or low risk etc.

Is it plausible that the human brain is adopting its own version of deep learning in its search for an answer to the myriad of problem situations that it confronts? It resorts to a process of "management" of memory and learning. Memory provides the ability to encode, store, retain and subsequently recall information and past experiences. Brain's consequently learns. A learning that depends on several criteria from time, long and short term learning, to transparency, explicit or implicit learning and depth of analysis, deep or generic learning.

These cognitive processes of the brain contribute to problem solving. Drucker's self-management problem provides an illustration.

\section{References}

[1]. Schacter, D.L. et al. (2009). Psychology, Second Edition. New York: Worth

[2]. "Wang, Y, Chiew V (2008), " On the cognitive process of human problem solving", Cognitive Systems Research (2008)

[3]. LeCun Y, Bengio Y, Hinton G. Deep learning. Nature. 2015

[4]. Goldstein F, Levin H (1987). "'Disorders of reasoning and problem- solving ability" in M. Meier, A. Benton, and L. Diller 
(Eds.), Neuropsychological rehabilitation. London: Taylor छ Francis Group.

[5]. Roman F. Loonis, et al., "A Meta-Analysis Suggests Different Neural Correlates for Implicit and Explicit Learning," Neuron, Volume 96, Issue 2, p52I-534.e7, iI October 20I7; doi:I0.I0I6/j.neuron.2017.09.032

[6]. Ford D, "How the brain learns", July 20, 20II

[7]. Understanding the brain, the birth of learning science, CERI, OECD, 2008

[8]. Understanding the brain, the birth of learning science, CERI, OECD, 2008).

[9]. HWikihow,ow to Exercise Your Brain for Better Thinking Skills Cor authored by wikiHow Staff | Reader-Approved | I26 References Updated: March 29, 2019

[10]. How the Brain Combines Memories to Solve Problems, Neuroscience news Sept 19,2018.

[11]. Yu Xuan Lee (2019)" Converting a Simple Deep Learning Model from PyTorch to TensorFlow", Towards Data Sciences, May 23, 20I9.

[12]. Types of Human Memory, July 8, 2020 The Human Memory 2010-2020

[13]. Deep Learning in Digital Pathology, 2nd February 2018, Jane Williams

[14]. http://www.global-engage.com/life-science/deep-learning-indigital pathology/

[15]. 'Drucker P, "Managing Oneself “, Harvard Business Review Classics, Jan 2008 